\title{
Prototype Hardware Implementation of a Boost Converter for DCMPFC
}

Dr.Abduljabbar Owaid Hanfesh Alshammery

Electromechanical Dept., University of Technology, Iraq, aljabbara.2007@yahoo.com

Submitted: $20 / 2 / 2017$

Accepted: 21/5/2017

\begin{abstract}
Power Factor Correction (PFC) is an essential feature of many AC/DC Power Electronics products. The issue of increasing the value of the Power Factor (PF) and increasing efficiency of transferring the power in such applications motivated this work. The integrated circuit NCP1014 was used to implement hardware of $20 \mathrm{~W}$ Discontinuous Conduction Modes Power Factor Correction (DCMPFC) prototype to be suitable to applications that require good performance, small size, low cost and high efficiency.In this work, a known inductive load is used, and measured the power factor with and without the proposed correction circuit, the results showed an improvement of the power factor up to $40 \%$. The presented results that have been tested in this paper were implemented in a laboratory to show the effectiveness of the proposed system.
\end{abstract}

Keywords: active converter, power factor, ac to dc converter, boosting converter.

\section{تنفيذ نموذج عملي لمبدل تعزيزي لتصحيح معامل القدرة بطريقة التوصيل المتقطع}

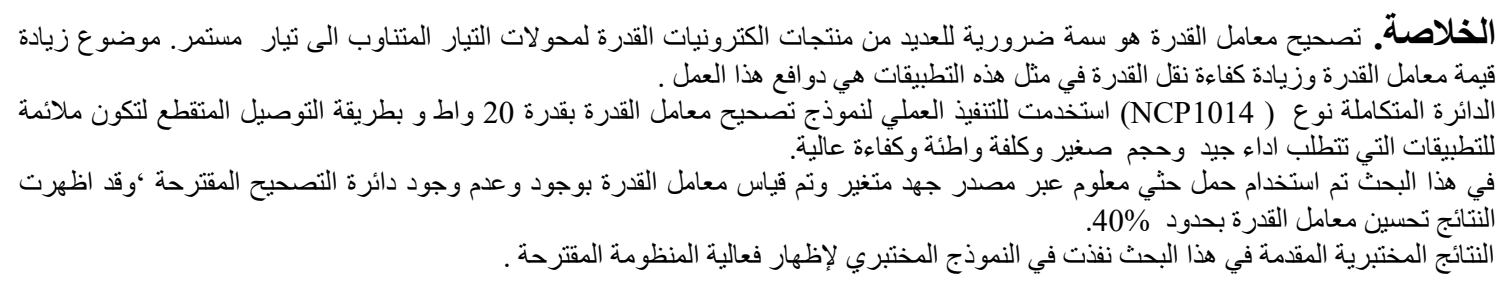

\section{Introduction:}

Within the last years, single phase AC / DC electric power converters have been gradually increased to use in the industry field, commercial, aerospace, housing, and military applications with most electronic equipment in domestic use ( $\mathrm{PC}_{\mathrm{S}}$, Copying Machine, Printers, TVS, telecommunication equipments), medical equipments and low power motors.etc; due to the feature of simplicity, high efficiency, small size and light weight. All the previous equipments contain, whether full-wave or halfwave rectifiers, and these rectifiers cause the generation of current harmonics. Consequently, this leads to the presence of severe problems that require several types of power conditioning in order to limit the harmonics content of input currents of electronic equipments connected to the power supply. One of the methods which is used for power conditioning is the power factor correction (PFC). [1-6].

Power factor improvement circuits are requisite for the AC/DC converters with adherence by the international standards requirements.

Many control techniques have been designed for single-stage PFC converters [7-12]. The recent researches have been producing an advanced control algorithms for power factor performance improvement, and methods to improve efficiency of circuit, and get the best PFC [5].

The main purpose of this paper is the implementation, development and studyof the performance of a Boost type topology of converter for a single phase rectifier at low power levels. This includes all the essential elements and control system that improves the PF according to Discontinuous current mode (DCM) technique.

\section{Classification of Power Factor Correction Methods}

In general, the correction techniques of power factor are classified into: 
(1) Passive circuit technique,

(2) Active circuit techniques

The passive method mostly relies on the use of an inductor or capacitor or both of them together to achieve PFC.This technique required a bulky components (inductors and capacitors) to increase the efficiency. Due to the time lag associated with the passive elements, it has a poor dynamic response. For these reasons, the passive power factor correction technique cannot achieve good power factor, and the output voltage cannot be controlled also. As a result of the above reasons, the active power factor correction techniques are the best way. [3], [13-14].

\subsection{Active method of PFC [4].}

The active method of a PFC, involves the following functions:

1 - The shaping of the input current is an active wave

2- High frequency switching Filtering.

3 - In order to control the input current source waveform the feedback sensing signal is used.

4 - Regulate the output voltage by feedback control.

The previous functions can be executed in one of the following techniques:

(1) PWM PFC techniques

(2) Variable frequency Resonant PFC techniques

(3) Soft switching PFC techniques

Shaping of the line current, by using switching device such as MOSFETs and IGBTs, is the popular technique.

Many circuits and control methods have been developed by using switched-mode topologies. The active PFC's employ six basic topologies of pulse width modulation techniques converters as in follows: Boost, Buck, Buck-Boost, Cuk, Sepic and Zeta

The boost converter is commonly used in PFC applications. [5], [15-22]. The design of boost converter is worked in three control modes: the first one is the continuous current mode (CCM), the second is critical current mode (CRM) and the third is discontinuous current mode (DCM), these names refer to the inductor current continuity within the switching cycle.

DCM boost PFC converter features zero-current turning on for the switch and no reverse recovery of diode, and it operates in constant switching frequency, which is beneficial for designing the inductor and EMI filter. The DCM PFC converter is widely used in low and medium power applications [23].

Figure 1 shows the simplified block diagram of single phase boost converter used to shape the line input current into more desirable waveform and to limit the output voltage[24 ].

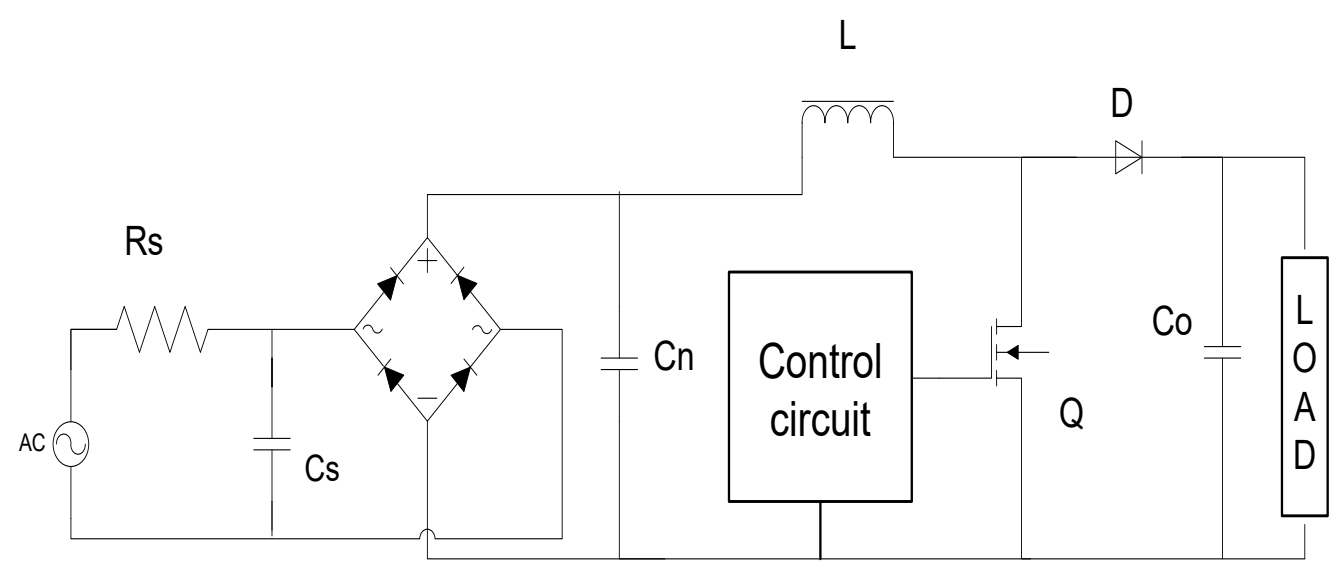

Figure 1 the block diagram of the boost active PFC converter[24]

The rectified line voltage (DC voltage) is applied to these electronics equipment. The starting process of a boost PFC converter design must be restricted to some specifications like, the range of input and 
output voltages, the range of frequency supply, and maximum output power. In general, the output voltage is higher than the max value of input voltage and the value of switching frequency must be chosen a high adequate value to make the circuit design small and minimize the value of distortion in line current waveform.

The selected value of indictor (L) that connected after the diode bridge rectifier must be chosen based on the permitted value of high frequency of the input current ripples. Capacitor and inductor are selected in the system design by using the following equations [3].

The duty cycle (D) of the MOSFET transistor switch:

$D=\frac{\mathrm{v}_{\mathrm{O}}-\mathrm{v}_{\mathrm{in}}}{\mathrm{v}_{\mathrm{O}}}$

From the above equation and because the $\mathrm{D}$ is a number between 0 and 1 , therefore the output voltage slightly is more than the input voltage.

To calculate the inductance L:

$L=\frac{\mathrm{V}_{\text {in }} \times \mathrm{D}}{\mathrm{f}_{\mathrm{s}} \times \Delta \mathrm{I}}$

Where fs is the switching frequency and $\Delta I$ is the change of current in a switching period.

The equation which expresses at the output capacitor value Co is:

$C_{O}=\frac{2 \times P_{O \times} \Delta t}{v_{o}^{2}-v_{i n}^{2}}$

\section{3-Hardware Implementation of proposed technique}

The hardware circuit design of the proposed boost power factor Converter which shown in Figure 2. The circuit is implemented as a boost active converter with a discontinuous current mode controller. The design uses the IC semiconductors NCP1014 monolithic, and a fixed frequency PWM converter which integrates the high power switch type MOSFET with limiting the internal current.

The PFC stage has pulsating input current, which gives electromagnetic interference (EMI) levels in the current which distorts the current wave form; this distortion is reduced by adding a large inductance of a passive LC filter in series with the main AC input.

In the proposed work the filter is used in two sides and comprised of C1, C2 and L1 is included to help attenuate conducted RFI line emissions. A diode bridge type BD1600V, 2A is used in order to rectify the AC input voltage of the inductor L2. MOSFET Q1 operate as an error amplifier to sense the output voltage via resistor divider R4/R5 and drive the feedback pin of $\mathrm{U}$,

The output of the capacitor C6 is given to the voltage regulator IC which stabilizes the voltage and gives a constant de voltage $400 \mathrm{~V}$. 


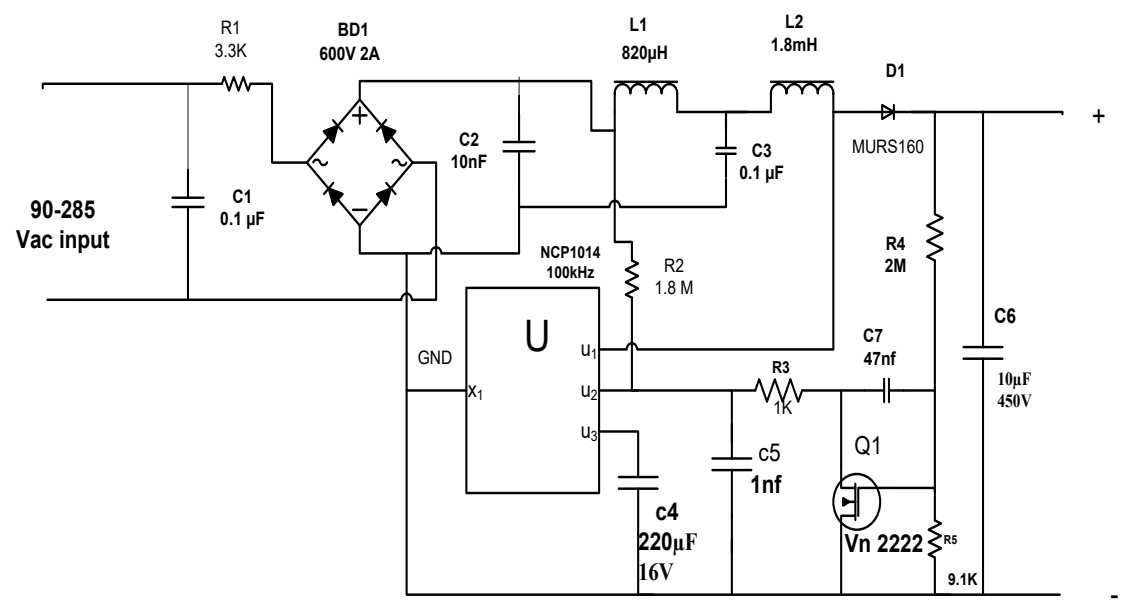

Figure 2: the hardware circuit design of PFC Converter

\section{4- Experimental Verification and results}

A 20 Watt output power laboratory prototype was built and tested for operation at variable input voltages. The prototype has the specifications of:

1) Input source voltage $V_{\text {in }}=90-285 \mathrm{~V} / 50 \mathrm{~Hz}$

2) Output voltage $V_{o}=400 \mathrm{~V}$.

3) Rated Output power $p_{\mathrm{o}}=20 \mathrm{~W}$

4) Switching period frequency fs $=100 \mathrm{kHz}$

Figure 3 shows the printed circuit board of proposed circuit

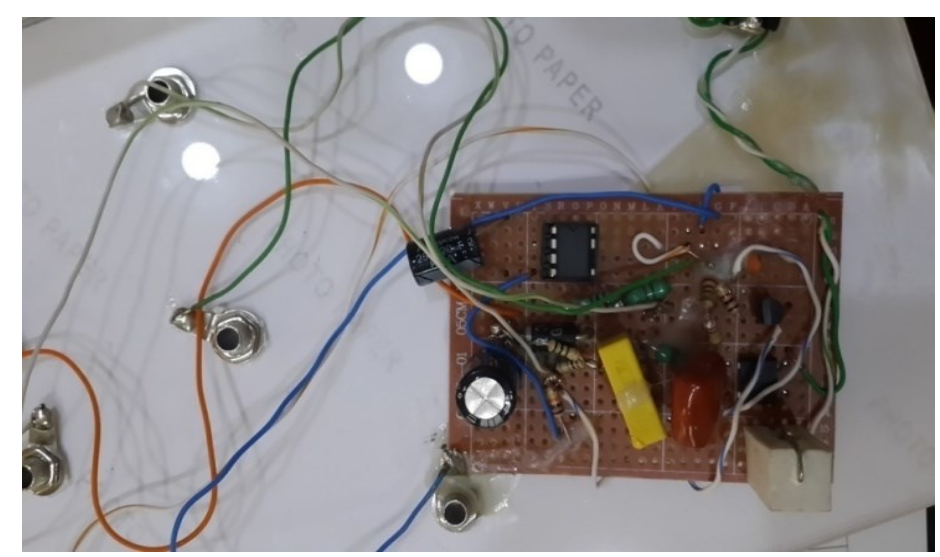

Fig. 3: the rectifier with PFC assembled on PCBs

Inductive load (chock coil) had been used to get a known power factor as shown in Figure 4, which shows the load connection with a variable voltage source and obtains the phase difference signals of voltage and current, as shown in Figure 5 which shows the phase difference of $90^{\circ}$.

To verify the validity of prototype system, the proposed system has been connected in parallel with a variable voltage supply (Variac) as shown in figure 6, the output voltage and output current waveforms are measured in figure 7 , the phase difference in this case is about $45^{\circ}$. It can be seen that the proposed 
circuit has contributed a $50 \%$ as a correction in power factor, as well as the current wave form is almost sinusoidal.

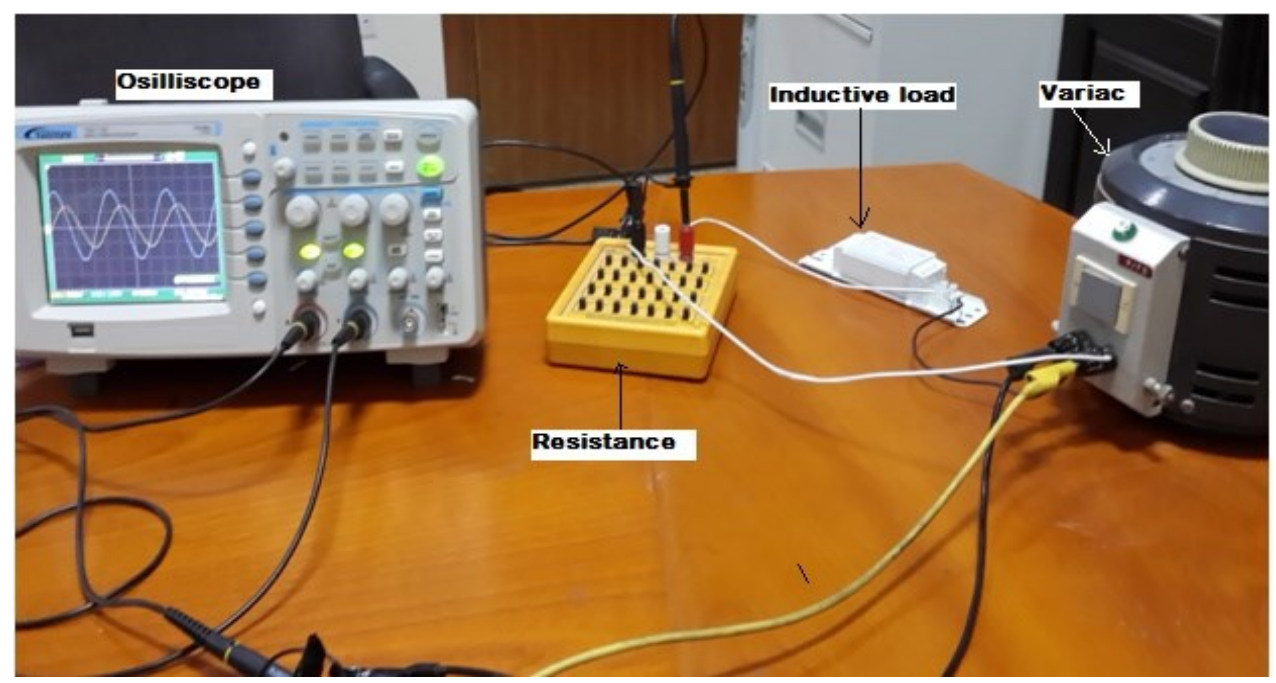

Fig. 4 the inductive load circuit

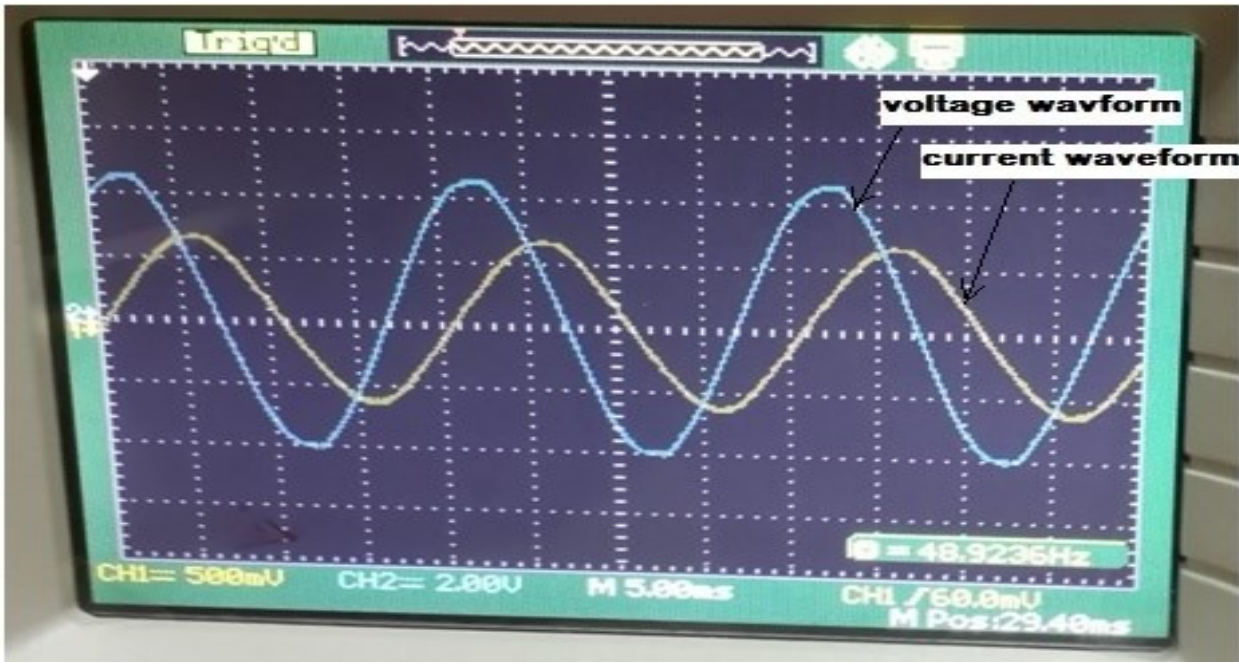

Fig. 5 the voltage and current waveform without proposed circuit 


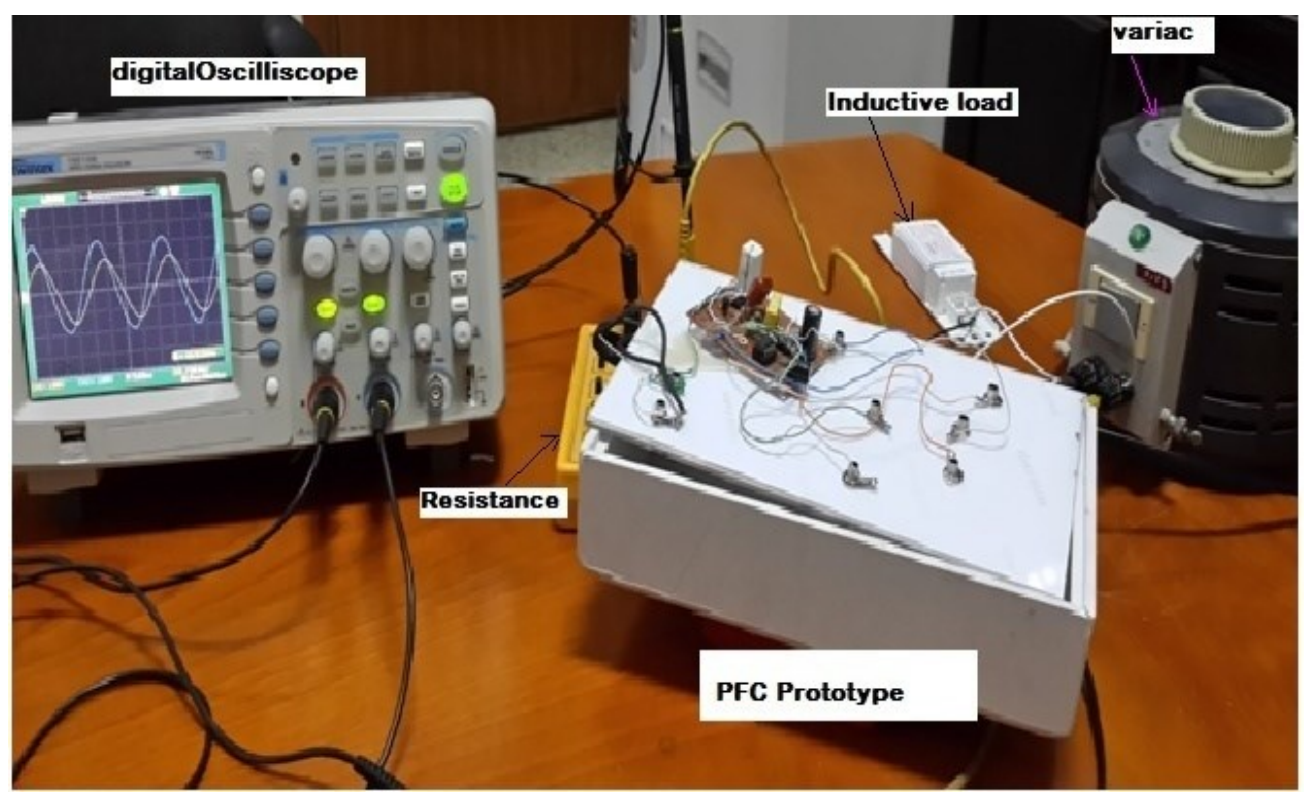

Fig. 6 the prototype circuit with inductive load

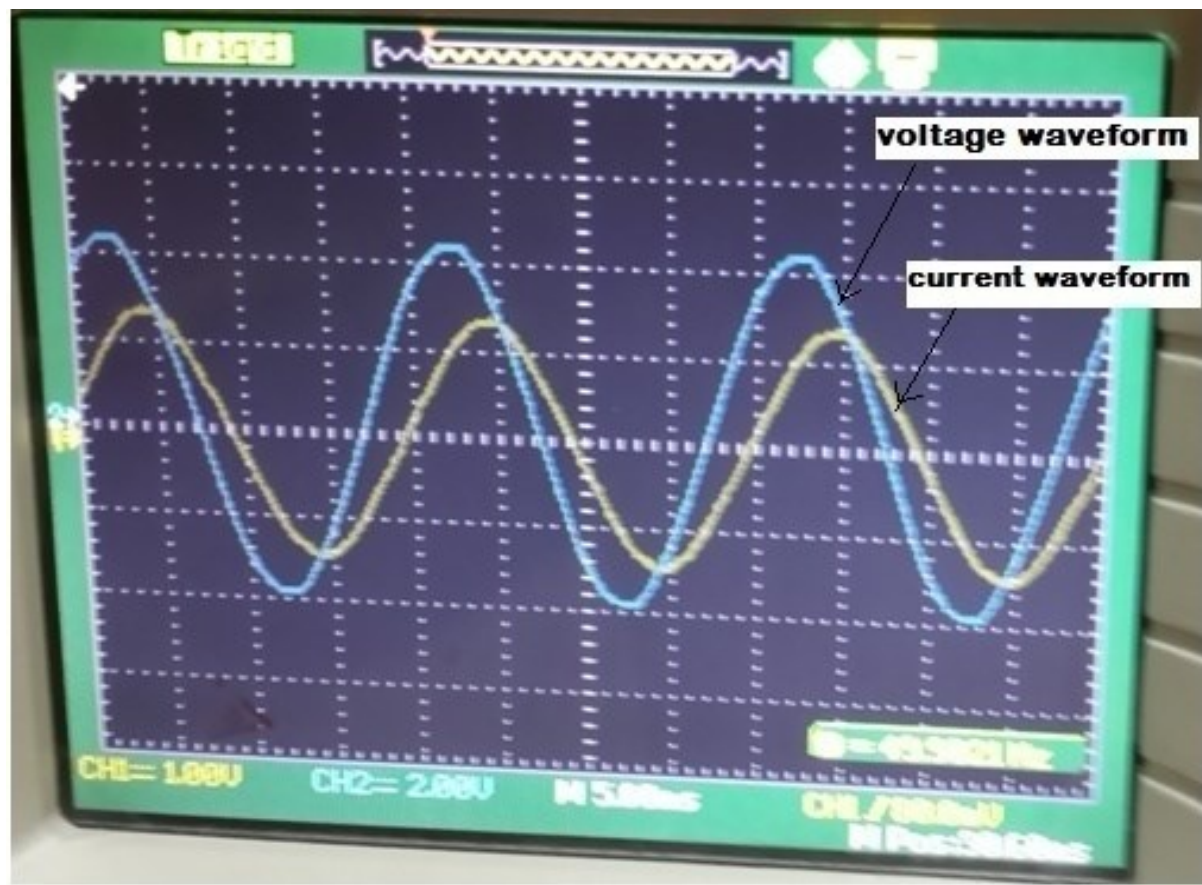

Fig. 7 the voltage and current waveforms with proposed circuit

Figure 8 shows the relationship between the measured output power and efficiency with variable input voltage. Figure 9 shows the measured power factor with output power.

As it can be seen from the experiment results and the curves obtained though there is a significant improvement in the power factor of the circuit and there is an improvement of converter efficiency, and the input current waveform is more sinusoidal. 


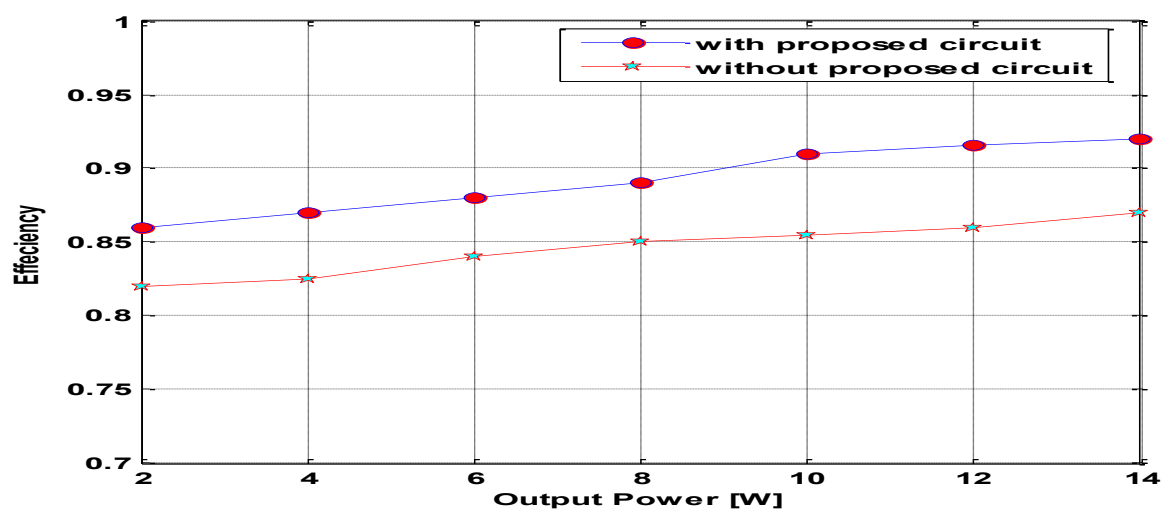

Fig. 8 measured efficiency and output power with and without proposed circuit

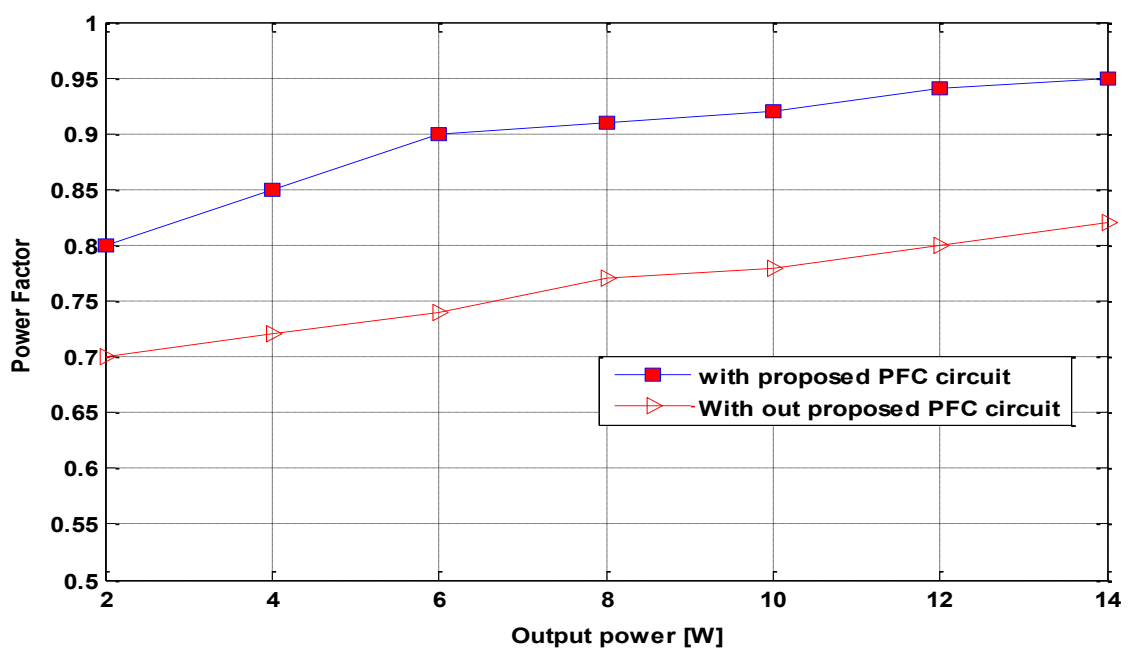

Fig. 9 the power factor and output power with and without proposed circuit

\section{Conclusions}

From the experimental results of the prototype, the following conclusions can be drawn:

1-The proposed PFC circuit has been improved the power factor of $40 \%$.

2-The proposed PFC circuit can be worked with high range of variable voltage supply (90 to285V), while maintaining a ratio improvement.

3-The result shows a fast output response of proposed circuit and its draws a sinusoidal current.

4-The PFC circuit has many advantages such as small size, simple structure, low cost and low weight.

5- The proposed PFC circuit can be used in many applications such as uninterrupted power supply (UPS), small batteries chargers, switching mode power supply, power supplies for telecommunication systems and test equipment's etc.

\section{References:}

[1]Yang-Line Chen, Yaow-Ming Chen "Line Current Distortion Compensation for DCM/CRM Boost PFC Converters “," IEEE Trans. Power Electronics, vol., no., pp., June, 2015.

[2] Moldaschl, J.; Broulim, J.; Palocko, L. "Boost power factor correction topology with average current control" ,IEEE, Applied Electronics (AE), International Conference , 2014, Pages: 213 - 216.

[3] Suma Umesh, L.Venkatesha, Usha “Active Power Correction Technique for Single Phase Full Bridge Rectifier”, IEEE, 2014. 
[4]A.K.Jaha, B.G.Fernandes, A.Kishore "A single Phase Single Stage AC/DC Converter with High Input Power Factor and Tight Output Voltage Regulation "Progress in Electromagnetic Research Symposium, Cambridge USA, March (26-29), 2006.

[5] Y.S. Kim, W.Y. Sung, and B.K. Lee, "Comparative Performance Analysis of High Density and Efficiency PFC Topologies," IEEE Trans. on Power Electronics, vol.29, no.6, pp.2666-2679, June 2014.

[6]Vijaya Vachak, Anula Khare,Amit Shrivatava" Power Factor Corrections Circuits: Active Filters "International Journal of Engineering Research and General Science Vol.2, No. 5, Aug.-Sep., 2014.

[7] C. Zhou and M.M. Jovanovic, "Design trade-offs in continuous current-mode controlled boost powerfactor correction circuits," in HFPC Conference, 1992, pp. 209-220.

[8] R. Redl and B. P. Erisman, "Reducing distortion in peak- current-controlled boost powerfactor correctors," in IEEE Applied Power Electronics Conference (APEC), 1994, pp. 576-583.

[9] C. Zhou, R.B. Ridley and F.C. Lee, "Design and analysis of a hysteretic boost power factor correction circuit," in IEEE Power Electronics Specialists Conference (PESC), 1990, pp. 800-807.

[10] W. Tang, Y. Jiang, G.C. Hua and F.C. Lee, "Power factor correction with flyback converter employing charge control," in IEEE Applied Power Electronics Conference (APEC), 1993, pp. 293-298.

[11] J.B. Williams, "Design of feedback loop in unity power factor AC to DC converter," in IEEE Power Electronics Specialists Conference (PESC), 1989, pp. 959-967.

[12] T.K. Jappe and S.A. Mussa, "Current technique applied in single phase PFC boost converter based on discrete-time one cycle control," in IEEE Telecommunications Energy Conference (INTELEC), 2011, pp. 1-5.

[13] Khalid Rustom and Issa Batarseh "Recent Advances in Single-Stage Power Factor Correction, IEEE, 2003.

[14]- Wei, H., "Single-Stage Single-Switch Power Factor Correction Circuits: Analysis, Design and Implementation, ” Ph.D. dissertation, University of Cenbal Florida, 1999.

[15] W. Cheng, J. Song, H. Li, and Y. Guo, "Time-Varying Compensation for Peak Current-Controlled PFC Boost Converter," IEEE Trans. Power Electronics, vol.30, no.6, pp.3431-3437, June 2015.

[16] A. Sanchez, A. de Castro, V.M. Lopez, F.J. Azcondo, and J. Garrido, "Single ADC Digital PFC Controller Using Precalculated Duty Cycles," IEEE Trans. Power Electronics, vol.29, no.2, pp.996-1005, Feb. 2014.

[17] Q. Ji, X. Ruan, and Z. Ye, "The Worst Conducted EMI Spectrum of Critical Conduction Mode Boost PFC Converter," IEEE Trans. Power Electronics, vol.30, no.3, pp.1230-1241, March 2015.

[18] H.S. Kim, J.K. Kim, K.B. Park, H.W. Seong, G.W. Moon, and M.J. Youn, "On/Off Control of Boost PFC Converters to Improve Light-Load Efficiency in Paralleled Power Supply Units for Servers," IEEE Trans. Industrial Electronics, vol.61, no.3, pp.1235-1242, March 2014.

[19] L. Huber, Yungtaek Jang, and M. M. Jovanovic, "Performance Evaluation of Bridgeless PFC Boost Rectifiers," IEEE Trans. Power Electronics, vol. 23, no. 3, pp. 1381-1390, May 2008.

[20] C.W. Clark, F. Musavi, and W. Eberle, "Digital DCM Detection and Mixed Conduction Mode Control for Boost PFC Converters," IEEE Trans. Power Electronics, vol.29, no.1, pp.347-355, Jan. 2014.

[21] J.W. Kim, H.S. Youn, and G.W. Moon, "A Digitally Controlled Critical Mode Boost Power Factor Corrector with Optimized Additional on Time and Reduced Circulating Losses," IEEE Trans. Power Electronics, vol.30, no.6, pp.3447-3456, June 2015.

[22] K.I. Hwu, H.W. Chen, and Y.T. Yau, "Fully Digitalized Implementation of PFC Rectifier in CCM without ADC," IEEE Trans. Power Electronics, vol.27, no.9, pp.4021-4029, Sept. 2012.

[23]Yao Kai,Hu Wenbin,Li Qiang ,Lyu Jaianguo" A Novel Control Scheme of DCM Boost PFC Converter" 2015.

[24]Supratim Basu and Math.H.J.Bollen, "A Novel Common Power Factor Correction Scheme for Homes and Offices," IEEE Transactions on Power Delivery, Vol.20, No.3, pp. 2257-2263, July 2005. 